\title{
Compact Dual-Band (2.4/5.2GHz) Monopole Antenna for WLAN Applications
}

\author{
A. Rathore ${ }^{*}$, R. Nilavalan, H. F. AbuTarboush and T. Peter \\ Wireless Networks and Communications Center (WNCC), School of Engineering and Design, Brunel University, \\ West London, UB8 3PH, UK
}

Hattan.AbuTarboush@brunel.ac.uk

\begin{abstract}
A compact and optimized design of a rectangular printed monopole antenna with slits and truncated ground plane on FR-4 substrate is presented. The proposed antenna is designed for dual-band operation at $2.4 \mathrm{GHz}$ and $5.2 \mathrm{GHz}$ for Wireless Local Area Network (WLAN) applications with $\mathrm{S}_{11}<-10 \mathrm{~dB}$. This antenna has good return loss and radiation characteristics in required frequency band. The proposed antenna gives omnidirectional radiation pattern in the $\mathrm{E}$ Plane and $\mathrm{H}$ plane over the frequency range of $2.4 \mathrm{GHz}$ and $5.2 \mathrm{GHz}$. The calculated and measured results in terms of return loss show good agreement and the results also show good wideband characteristics.
\end{abstract}

\section{INTRODUCTION}

Wireless communication systems are becoming more popular now-a-days, and have been developed rapidly over the last decade. As with new developments, there has been an increased demand for high data rate and reduced sized antennas. The printed monopole antenna has become very popular because of its low cost factor and fabrication simplicity. Printed monopole antenna can easily be integrated in communication systems and fabricated on printed circuit boards e.g. fabricated on laptops for WLAN applications. The future communication system will need multi-band or wide-band antenna designs to satisfy the increasing demand of various applications. One of the most popular emerging technologies is WLAN wherein IEEE 802.11 WLAN standards specify two operating frequencies i.e. $2.4(2400-2484 \mathrm{MHz})$ and $5.2 \mathrm{GHz}(5150-5350 \mathrm{MHz})$. Hence in order to satisfy the IEEE standard dual band printed monopole antennas are required, which can transmit and receive signals simultaneously in these two bands, especially in cases where devices like laptops move from one cell to other with different operating frequency band, where a dual band antenna can be very useful.

In last a few years some printed monopole antennas for WLAN applications such as inverted F strip [1], straight radiating strip [2] have been designed but these antennas [1,2] are only capable of single band operations [3]. But it has been seen that dual band monopoles such as Double T shaped monopole [3] U shaped monopoles [4], ring monopole [5]; and L- shaped monopole [6] also appeared in the literature.

In this paper, we propose a new and simple dual band printed monopole antenna. The antenna consists of two rectangular monopole elements; stacked at the top of each other, and with a ground plane at the back of the substrate (see Fig. 1). The main resonators of the antenna are two rectangular elements with different sizes and designed to operate approximately dual band at 2.4 and $5.2 \mathrm{GHz}$. Furthermore slits are introduced to improve the S11 response and impedance bandwidth. The proposed antenna can easily be fed with $50 \Omega$ microstrip line. More details on antenna design and the prototype of the design will be elaborated hereinafter.

\section{DESIGN PROCEDURE}

As shown in figure 1, the proposed antenna has two rectangular elements having different shapes which are stacked on each other, is fed by $50 \Omega$ microstrip line of width $\mathrm{W}_{\mathrm{t}}=3 \mathrm{~mm}$ and length $\mathrm{L}_{3}=12.5 \mathrm{~mm}$. These rectangular monopole elements were printed on one side of the FR4 substrate of thickness $1.57 \mathrm{~mm}$, length $\mathrm{L}=45 \mathrm{~mm}$, width $\mathrm{W}=35 \mathrm{~mm}$, and with relative permittivity of 4.4 . The ground plane was printed on the other side of the substrate with length $\mathrm{L}_{\mathrm{g}}=6.5 \mathrm{~mm}$ and width of $35 \mathrm{~mm}$.

In this antenna design the smaller rectangular monopole element controls the higher order operating mode of the proposed antenna. Smaller rectangular monopole has a width of $\mathrm{W}_{2}=10 \mathrm{~mm}$ and length of $\mathrm{L}_{2}=10$ $\mathrm{mm}$. The bigger rectangular monopole element is used to control the lower order operating mode of the antenna, with width $\mathrm{W}_{1}=15 \mathrm{~mm}$ and length $\mathrm{L}_{1}=13 \mathrm{~mm}$. From figure 1 it can be noticed that the upper rectangular monopole element is stacked with same center as the lower one, with outward edges of $2.5 \mathrm{~mm}$ on both left and right sides. This arrangement is most suitable in terms of getting best possible return loss $\mathrm{S}_{11}$ and impedance bandwidth. 


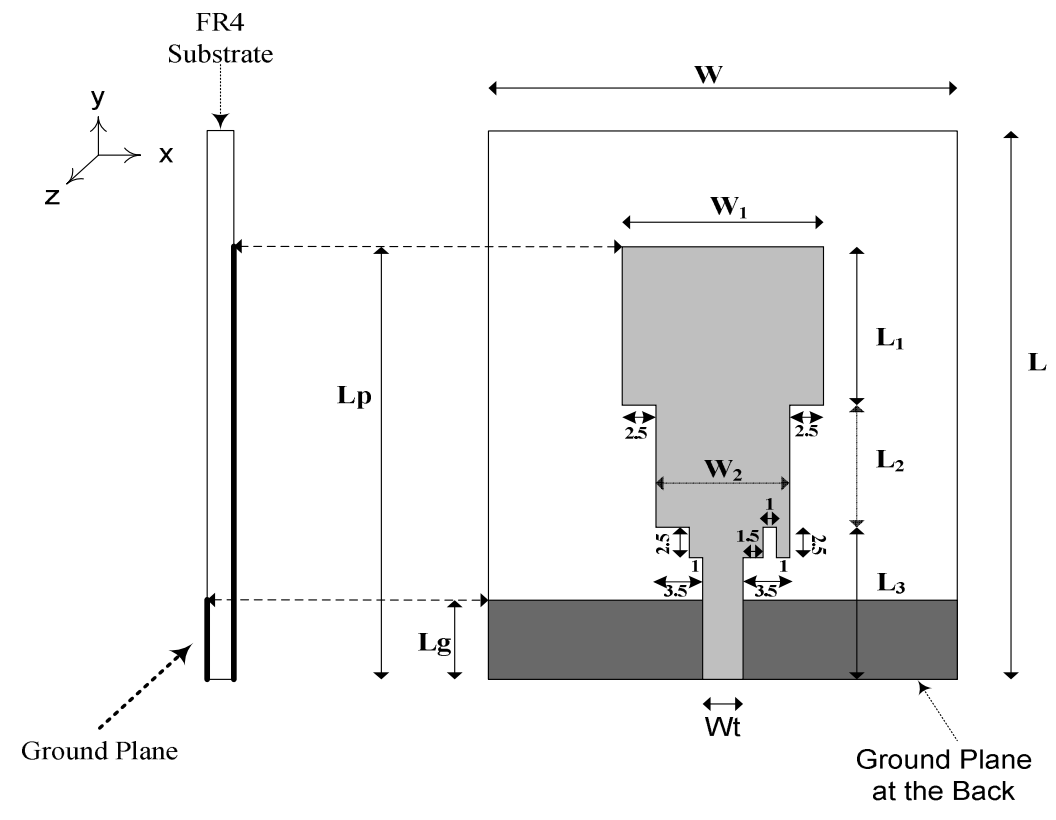

Fig. 1 Geometry of the proposed dual band antenna

Furthermore, small metallic elements were added on the side of the microstrip line to shift the operating frequency for WLAN applications and to improve the response. As in figure 1 a small metallic element was added towards the left of the microstrip line with width $=1 \mathrm{~mm}$ and length $=2.5 \mathrm{~mm}$. Whereas on the right hand an element of width $3.5 \mathrm{~mm}$ and length of $=2.5 \mathrm{~mm}$ is added, but a $1 \mathrm{~mm}$ wide and $2.5 \mathrm{~mm}$ length slit was also added at a $1.5 \mathrm{~mm}$ separation towards right hand side from the microstrip line. By these extra elements the $S_{11}$ response and impedance bandwidth is further improved. Additionally the shape and the size of the ground plane can also affect the operating frequency and the operating bandwidths of the two bands. Hence the ground plane parameters were also adjusted for better dual band response.

Following table 1 shows the complete dimensional data.

Table 1 Complete Dimensional Data

\begin{tabular}{|c|c|l|}
\hline Symbol & Value (mm) & \multicolumn{1}{|c|}{ Comments } \\
\hline $\mathbf{W}$ & 35 & Substrate width \\
\hline $\mathbf{L}$ & 45 & Substrate length \\
\hline $\mathbf{W}_{\mathbf{t}}$ & 3 & Width of microstrip line \\
\hline $\mathbf{W}_{\mathbf{1}}$ & 15 & Upper rectangular element width \\
\hline $\mathbf{W}_{\mathbf{2}}$ & 10 & Lower rectangular element width \\
\hline $\mathbf{L}_{\mathbf{1}}$ & 13 & Upper rectangular element length \\
\hline $\mathbf{L}_{\mathbf{2}}$ & 10 & Lower rectangular element length \\
\hline $\mathbf{L}_{\mathbf{3}}$ & 12.5 & Length of microstrip line \\
\hline $\mathbf{L}_{\mathbf{p}}$ & 35.5 & Total length of the element \\
\hline $\mathbf{L}_{\mathbf{g}}$ & 6.5 & Length of the ground plane \\
\hline
\end{tabular}




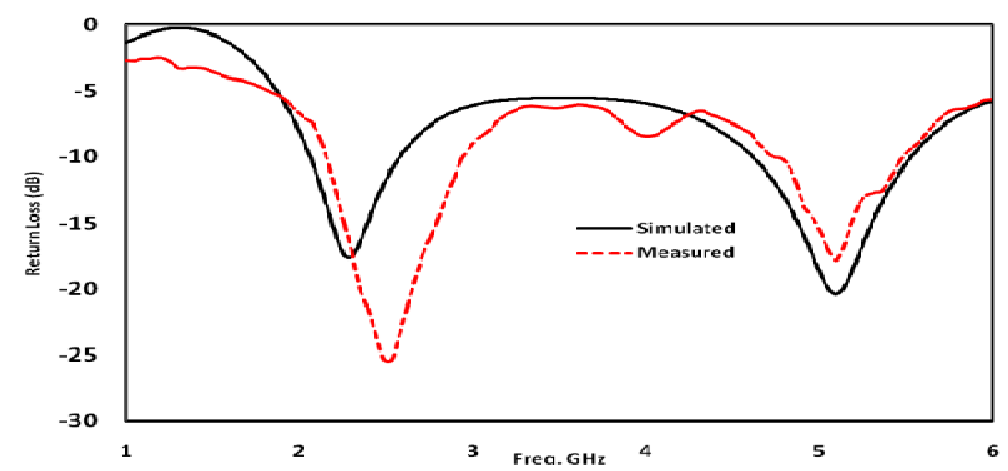

Fig. 2 Simulated and Measured Return loss characteristics of the proposed antenna

\section{SIMULATED AND MEASURED RESULTS}

The proposed antenna was designed and simulated using CST microwave studio and the results are discussed below. Figure 2 and 6 show simulated result with CST and measured result of the return loss characteristics of the proposed antenna.

As shown in figure 2, the proposed antenna is working on two frequencies. The measured and simulated response around at $5.12 \mathrm{GHz}$ frequency agree very well while at the lower frequency, the measured response is slightly shifted to $2.45 \mathrm{GHz}$. Fabrication tolerances can be the reason for this mismatch. In terms of the $10 \mathrm{~dB}$ impedance bandwidth, at $2.4 \mathrm{GHz}$ measured response has an impedance bandwidth of $760 \mathrm{MHz}$ (i.e. $2.17 \mathrm{GHz}-2.93 \mathrm{GHz}$ ) and at $5.2 \mathrm{GHz}$ the impedance bandwidth is $720 \mathrm{MHz}$ (i.e. $4.78 \mathrm{GHz}-5.5 \mathrm{GHz}$ ). The radiation patterns were simulated and results are shown in figure 3 and 4.
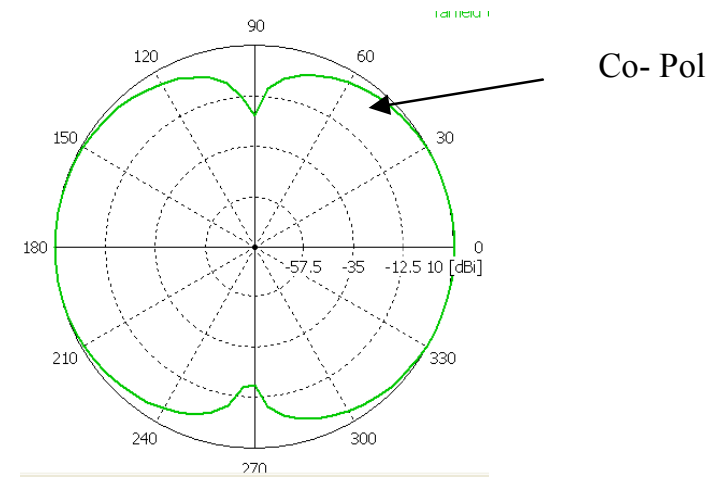

Fig. 3(a) Radiation pattern of $\mathrm{H}$ Plane for $2.4 \mathrm{GHz}$

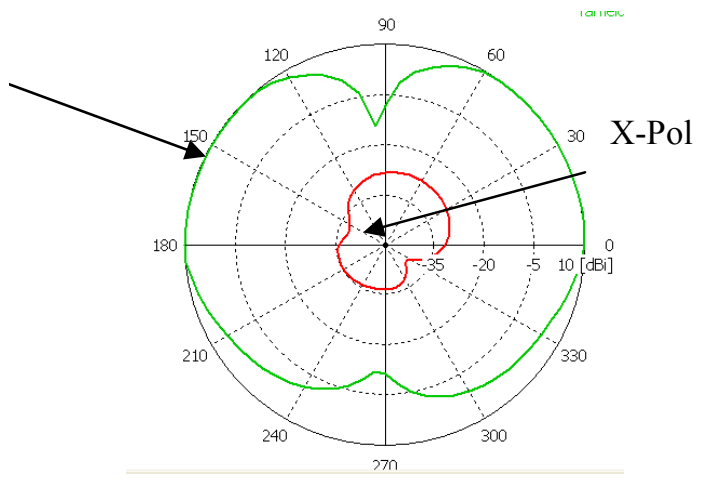

(b) Radiation pattern of $\mathrm{H}$ plane for $5.2 \mathrm{GHz}$

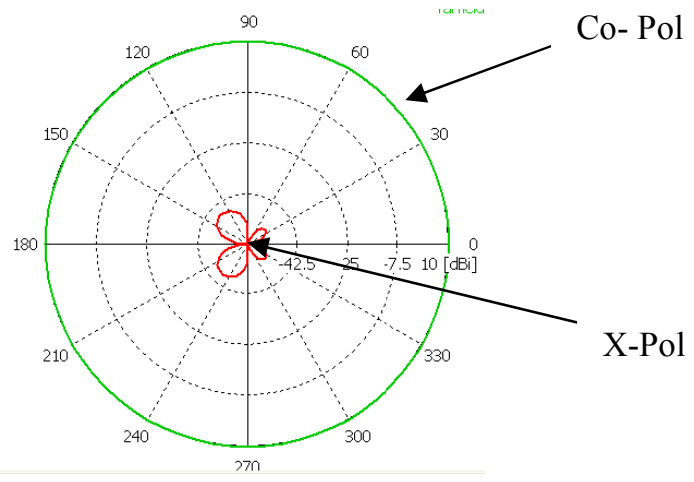

Fig.4 (a) Radiation pattern for E plane $2.4 \mathrm{GHz}$

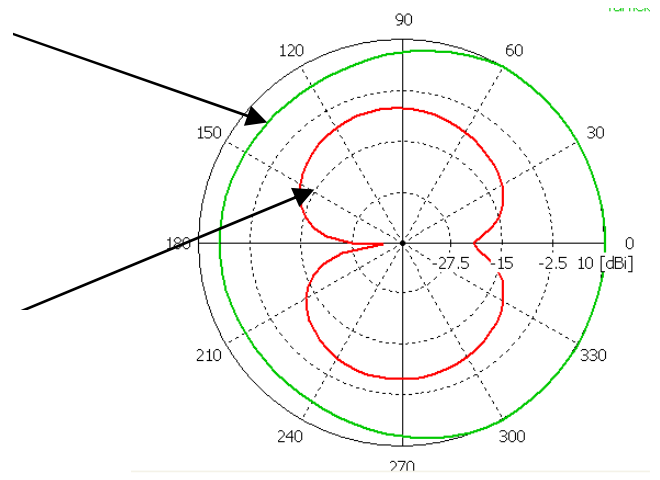

(b) Radiation pattern of $E$ plane for $5.2 \mathrm{GHz}$ 
From figure 3 and 4 it may be observed that the co polarization component of radiation pattern in both $\mathrm{E}$ and $\mathrm{H}$ planes for $2.4 \mathrm{GHz}$ and $5.2 \mathrm{GHz}$ are nearly omni-directional with low cross polar components in $\mathrm{E}$ and $\mathrm{H}$ planes. However, the cross polar component is high in $\mathrm{E}$ and $\mathrm{H}$ plane at $5.2 \mathrm{GHz}$. The directivity for $2.4 \mathrm{GHz}$ and $5.2 \mathrm{GHz}$ are $2.24 \mathrm{dBi}$ and $3.87 \mathrm{dBi}$ respectively. The Fabricated antenna and its response under test is shown in figure 5 and 6.

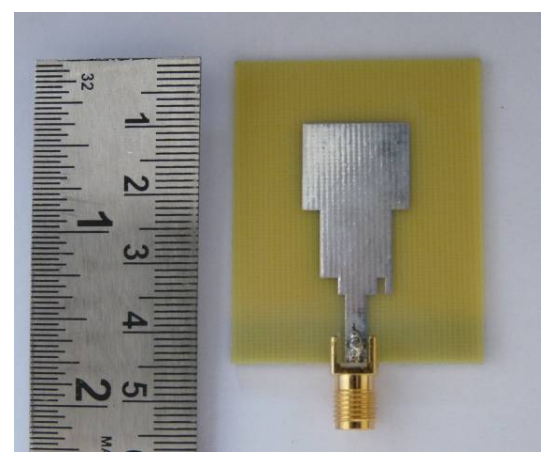

Fig. 5 Realized photograph

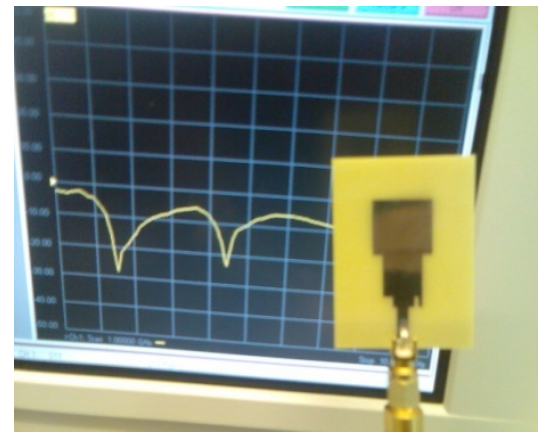

Fig. 6 Fabricated antenna tested

\section{CONCLUSION}

This paper presents the design of a printed monopole antenna for dual band operation. This design is suitable for WLAN applications at $2.4 \mathrm{GHz}$ and $5.2 \mathrm{GHz}$. Results of simulated and measured return loss, impedance bandwidth and the radiation pattern at the operating frequencies are obtained. The proposed design monopole elements parameters are fully adjusted to get the best possible response for dual band operations.

\section{REFERENCES}

[1] M. Ali and G. J. Hayes, "Analysis of integrated inverted-F antennas for Bluetooth applications," in Proc. 2000 IEEE-APS Conf. on Antennas Propagation for Wireless Communications, Waltham, MA, pp. 2124.

[2] L. M. Burns and C. L. Woo, "Dual orthogonal monopole antenna system,” U.S. Pat. 5990 838, Nov. 23, 1999.

[3] Y. L. Kuo and K. L. Wong, "Printed Double-T monopole antenna for 2.4/5.2 GHz dual-band WLAN operations," IEEE Transactions on Antennas and Propagation, VOL. 51, NO. 9, September 2003.

[4] F. Chen and C. M. Peng, "Microstrip-fed dual-U-shaped printed monopole antenna for dual-band wireless communication applications, " Electron Letter, vol. 39, pp. 955-956, 2003.

[5] G. Zhao, F.-S. Zhang, Y. Song, Z.-B. Weng, and Y.-C. Jiao, "Compact ring monopole antenna with double meander lines for 2.4/5ghz dual-band operation," Progress In Electromagnetics Research, PIER 72, 187-194, 2007.

[6] Hua-Ming Chenl and Yi-Fang Lin, "Printed Monopole Antenna for 2.4/5.2 GHz Dual-band Operation," IEEE transaction on antenna and propogation society international symposium 2003, VOL. 3, 60-33, Jun 2003. 